\title{
Electrochemical Study of the Synergistic Effect of Two Copper Corrosion Inhibitors, Nicotinic Acid (NAC) and Nicotinamide (NAM) in Two Different Media
}

\author{
Yapi Serge Brou ${ }^{*}$, Nagnonta Hippolyte Coulibaly ${ }^{1}$, N'Guessan Yao Silvère Diki $^{1}$, Juan Creus ${ }^{2}$, \\ Albert Trokourey ${ }^{1}$ \\ ${ }^{1}$ Laboratoire de Chimie Physique (LCP), Université Félix Houphouët-Boigny d’Abidjan, Abidjan, Côte d'Ivoire \\ ${ }^{2}$ Laboratoire des Sciences de l'Ingénieur pour l'Environnement (LaSIE) UMR 7356 CNRS, Université de La Rochelle, \\ La Rochelle, France \\ Email: *lesaintbys@yahoo.fr
}

How to cite this paper: Brou, Y.S., Coulibaly, N.H., Diki, N'G.Y.S., Creus, J. and Trokourey, A. (2019) Electrochemical Study of the Synergistic Effect of Two Copper Corrosion Inhibitors, Nicotinic Acid (NAC) and Nicotinamide (NAM) in Two Different Media. Open Journal of Physical Chemistry, 9, 193-203.

https://doi.org/10.4236/ojpc.2019.94011

Received: September 19, 2019

Accepted: October 28, 2019

Published: October 31, 2019

Copyright $\odot 2019$ by author(s) and Scientific Research Publishing Inc. This work is licensed under the Creative Commons Attribution International License (CC BY 4.0).

http://creativecommons.org/licenses/by/4.0/

\begin{abstract}
Inhibitive properties of NAC and NAM as well as their mixture have been investigated in two different corrosive media through potentiodynamic polarization and electrochemical impedance spectroscopy at $298 \mathrm{~K}$. These electrochemical measurements indicate that the inhibition efficiency increases with the concentration for each of the inhibitors used separately as well as for their mixture. In both cases, the combination behaves as mixed type inhibitor with a great cathodic tendency. $\mathrm{NaCl} 3.5 \%$ highlights an antagonist effect of NAM which reduces the effectiveness of NAC whereas $\mathrm{HNO}_{3} 1 \mathrm{M}$ shows a synergistic effect between them.
\end{abstract}

\section{Keywords}

NAC, NAM, Antagonist Effect, Synergistic Effect

\section{Introduction}

Copper and its alloys are often used in many industrial applications [1] [2] [3]. Copper is a relatively noble metal; however, it undergoes corrosion when being in contact with saline and acidic solutions, especially in the presence of oxygen, chloride or other oxidants. The behavior of copper and its alloys in these media is extensively reported in literature [4] [5] [6] and the several schemes have been presented for their dissolution. Organic heterocyclic compounds [7] have been reported to be effective inhibitors for copper corrosion in acid medium. The na- 
ture of the corrosive inhibitor depends on the material being protected and on the corrosive agent to neutralize. These heterocyclic compounds [8] are employed as corrosion inhibitors because of the presence of many adsorption centers (O, N, S, P, and $\pi$ electrons) which can help to form complexes with metal ions. These complexes constitute a film barrier which separates the metal from the aggressive environment. With increased awareness towards environmental pollution and control, the search for less toxic and environmentally friendly corrosion inhibitors is becoming increasingly important [9]. Thus, researchers have carried out many works that have focused on several drugs including vitamins. The main objective of this work is the study of the synergistic effect of the two forms of vitamin $\mathrm{B} 3$ that are: nicotinicacid $\left(\mathrm{C}_{6} \mathrm{H}_{5} \mathrm{NO}_{2}\right)$ and nicotinicamide $\left(\mathrm{C}_{6} \mathrm{H}_{6} \mathrm{~N}_{2} \mathrm{O}\right)$ (Scheme 1) on the corrosion of copper in 3.5\% NaCl medium [10] [11] simulating sea water as well as in one molar nitric acid medium.

\section{Materials and Methods}

\subsection{Samples}

The cylindrical samples of copper of $99.99 \%$ purity were mounted in glass tubes of suitable diameter to provide an exposed active geometrical surface area of 3.14 $\mathrm{cm}^{2}$ (diameter $\left.=1 \mathrm{~cm}\right)$ to the corrosive medium. Prior to each test, copper substrates were polished with abrasive papers of decreasing particle size (400, 800, 1000,1200 and 2000), rinsed with Milli-Q water $(18.2 \mathrm{M} \Omega \cdot \mathrm{cm})$, degreased with ethanol and then rinsed again with Milli-Q water and dried in air.

\subsection{Solutions}

The saline corrosive medium consists of a $3.5 \%$ sodium chloride solution which is obtained by dissolving sodium chloride (99.5\%) Sigma-Aldrich (provides in France) in deionized water. The aggressive $1 \mathrm{M} \mathrm{HNO}_{3}$ solution was prepared by dilution of analytical grade 69\% nitric acid PANREAC (provides in France) with distilled water. The analytical nicotinic acid and nicotinamide were purchased from Sisco Research Laboratories Pvt. Ltd. The solutions of concentration 10 $\mathrm{mM}$ were prepared by dilution. All tests are carried out in solutions with magnetic and aerated stirring. A Thermo-cryostat Lauda model E100 permits to keep the electrolyte at the fixed temperature.

\subsection{Electrochemical Measurements}

The electrochemical measurements were performed in a three-electrode cell with a volume of $0.5 \mathrm{~L}$. The working electrode (WE) was copper samples, the counter<smiles>NC(=O)c1cccnc1</smiles>

Scheme 1. NAC (left) and NAM (right). 
electrode (CE) was a platinum wire and the reference (Ref) electrode was a saturated calomel electrode (SCE: $0.241 \mathrm{~V}$ vs SHE). The electrochemical study (potentiodynamic polarization and electrochemical impedance spectroscopy (EIS)) of the behavior of copper in contact with the corrosive medium in the absence or in the presence of inhibitors (single or mixture)was carried out using an experimental device composed of a Potentiostat-Galvanostat MODULAB, a DELL computer equipped with MODULAB XM ECS software allowing data processing.

\subsubsection{Potentiodynamic Polarization Measurements}

The potentiodynamic current-potential curves were recorded by changing the electrode potential automatically from -300 to $150 \mathrm{mV}$ with a scan rate of 0.2 $\mathrm{mV} \cdot \mathrm{s}^{-1}$.

\subsubsection{Electrochemical Impedance Spectroscopy (EIS)}

The impedance measurements were carried out at $25^{\circ} \mathrm{C}$ after 60 minutes of immersion in each electrolyte (3.5\% NaClor $1 \mathrm{M} \mathrm{HNO}_{3}$ solution) with or without inhibitor. The amplitude of the applied sinusoidal voltage to the drop potential is $10 \mathrm{mV}$ peak-to-peak at frequencies between $10^{-2}$ and $6.10^{4} \mathrm{~Hz}$ with 10 points per decade. Impedance data has been analyzed and fitted by using Z View $2.3 \mathrm{im}-$ pedance software. All the impedance diagrams were performed in potentiostatic mode at the open circuit potential and presented in the Nyquist diagram (Re-jIm) where Re is the real and -jIm is the imaginary part in Bode plan.

\section{Results and Discussion}

\subsection{Synergistic Effect between NAC and NAM in 3.5\% NaCl Medium through Potentiodynamic Polarization}

Figure 1 shows the polarization curves of copper immersed in $3.5 \% \mathrm{NaCl}$ in the absence and in the presence of inhibitors: $10 \mathrm{mM} \mathrm{NAC,} 10 \mathrm{mM}$ NAM and 10 mM NAC + 10 mM NAM.

In the absence of inhibitors, the corrosion potential is approximately -225 $\mathrm{mV} / \mathrm{SCE}$. In the cathode field, a first regime is observed up to $-40 \mathrm{mV} / \mathrm{SCE}$ where a linear variation of the current density with respect to the potential is observed. This evolution corresponds to the reaction of reduction of the oxygen at the surface of the copper. For higher cathodic potentials, a reduction peak is observed, which could be associated with the reduction of the copper oxides formed during the immersion period. A linear variation of the current density with respect to the potential is observed in the anode domain. With the addition of inhibitors, the shape of the polarization curves is quite similar. Both for the inhibitors alone and for the mixture, the corrosion potential is shifted towards more to cathodic potentials. This displacement is associated with a remarkable decrease in current density compared to that obtained in the solution without inhibitor with a modification of the cathodic Tafel slope values. It may also be noted that the anodic polarization curves are not strongly affected by the 


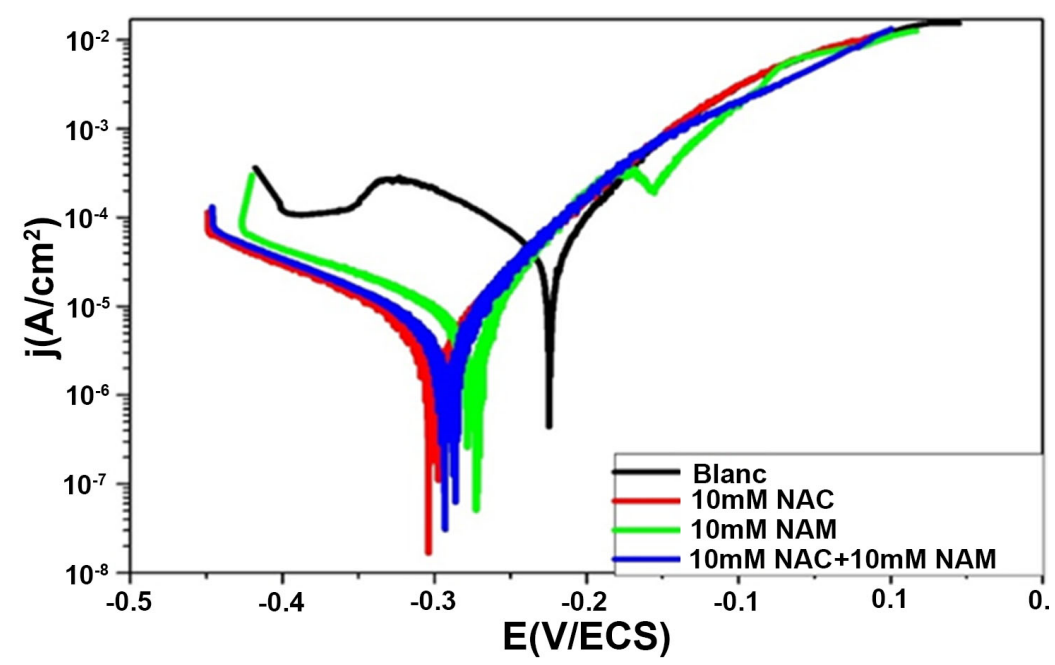

Figure 1. Polarization curves of copper immersed in $3.5 \% \mathrm{NaCl}$, in the absence and presence of inhibitors.

presence of the inhibitors alone and their mixture. The electrochemical parameters of copper corrosion in $3.5 \% \mathrm{NaCl}$ in the absence or presence of inhibitors at $298 \mathrm{~K}$ are shown in Table 1.

The cathodic Tafel slope (bc) changes significantly with the addition of the mixture while the variation of anodic Tafel slope (ba) is slightly modified, indicating that the mixture can modify the mechanisms of reduction of oxygen and on the other hand, it acts by the formation of a barrier by its molecules between the metal and the aggressive medium. The difference in corrosion potential between the solution without inhibitor and that with the mixture is about 65 $\mathrm{mV} / \mathrm{SCE}$ towards the cathodic direction. The mixture can be considered as a mixed type inhibitor for copper in $3.5 \% \mathrm{NaCl}$ solution [12] It can also be seen from Table 1 that the corrosion current density obtained with the combined inhibitors is lower than that of NAM but higher than that obtained with NAC. In addition, it is found that the NAM slightly decreases the performance of NAC where the inhibition efficiency decreases from $88 \%$ to $85 \%$. In the light of this information, NAM has an antagonistic effect with NAC action [13].

\subsection{Study of the Synergistic Effect between NAC and NAM in 1M $\mathrm{HNO}_{3}$ Medium}

\subsubsection{Potentiodynamic Polarization}

Figure 2 shows the polarization curves of copper immersed in $1 \mathrm{M} \mathrm{HNO}_{3}$, in the absence and presence of inhibitors.

From Figure 2, showing the polarization curves of copper in $1 \mathrm{M} \mathrm{HNO}_{3}$ in the absence and presence of nicotinic acid (NAC), nicotinamide (NAM) and their synergy, it can be noted for the curve without inhibitor, that the corrosion potential has a value of $-40 \mathrm{mV} / \mathrm{SCE}$, in the cathodic branch. The appearance of a passivation stage of $-70 \mathrm{mV} / \mathrm{SCE}$ up to $-110 \mathrm{mV} / \mathrm{SCE}$ followed by an increase in current density. The copper corrosion current density in the solution without inhibitor is about $80 \mu \mathrm{A} / \mathrm{cm}^{2}$ in agreement with the literature [14]. 
Table 1. Electrochemical parameters of copper corrosion in $3.5 \% \mathrm{NaCl}$ in the absence or presence of inhibitors at $298 \mathrm{~K}$.

\begin{tabular}{ccccccc}
\hline Concentration & $\begin{array}{c}\mathrm{E}_{\text {corr }} \\
(\mathrm{mV} / \mathrm{SCE})\end{array}$ & $\begin{array}{c}\mathrm{j}_{\text {corr }} \\
\left(\mu \mathrm{A} \cdot \mathrm{cm}^{-2}\right)\end{array}$ & $\begin{array}{c}\mathrm{b}_{\mathrm{a}} \\
(\mathrm{mV} / \mathrm{dec})\end{array}$ & $\begin{array}{c}-\mathrm{b}_{\mathrm{c}} \\
(\mathrm{mV} / \mathrm{dec})\end{array}$ & $\begin{array}{c}\mathrm{CR} \\
(\mathrm{mm} / \mathrm{an})\end{array}$ & $\begin{array}{c}\eta \\
(\%)\end{array}$ \\
\hline 0 & -225 & 46.5 & 48 & 94 & 0.544 & - \\
10 mM NAC & -300 & 5.6 & 69 & 138 & 0.065 & 88 \\
10 mM NAM & -274 & 9.0 & 55 & 186 & 0.105 & 80 \\
Mixture & -290 & 7.0 & 74 & 157 & 0.082 & 85 \\
\hline
\end{tabular}

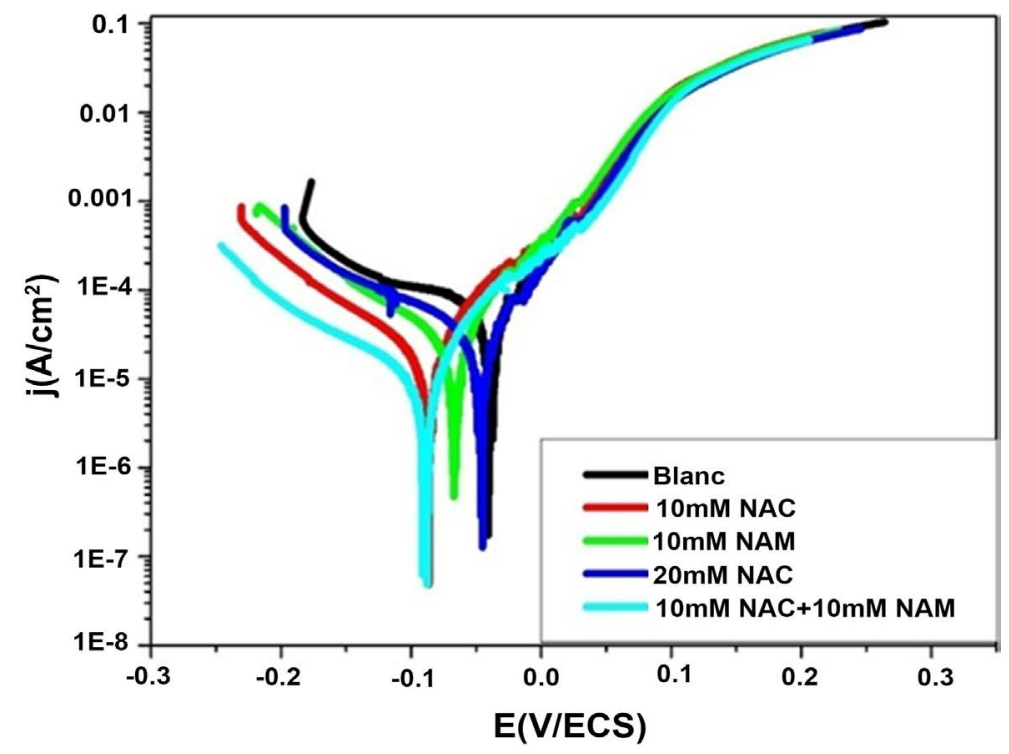

Figure 2. Polarization curves of copper immersed in $1 \mathrm{M} \mathrm{HNO}_{3}$, in the absence and in the presence of inhibitors.

In the presence of $10 \mathrm{mM} \mathrm{NAC}, 10 \mathrm{mM} \mathrm{NAM}$ and the mixture, the corrosion potential moves to negative values $-85 ;-67 ;-90 \mathrm{mV} / \mathrm{SCE}$, respectively, and in the anode field, the anodic branches are almost confused with that of inhibitor. Given the variation of the potential with respect to the blank, it can be assumed that the two inhibitors as well as their combination behave as mixed type inhibitors. In the cathodic branch, a diffused plateau was observed with the addition of inhibitors alone and combined accompanied by a sharp decrease in the current density.

Table 2 indicates the synergistic factor, inhibition efficiencies and electrochemical parameters for copper polarization curves in $1 \mathrm{M} \mathrm{HNO}_{3}$ in the absence and presence of inhibitors at $298 \mathrm{~K}$.

According to Table 2, the electrochemical parameters deduced from the polarization curves of the copper immersed in $1 \mathrm{M} \mathrm{HNO}_{3}$ in the absence and presence of inhibitors, we observe a better inhibition efficiency (86\%) for the combination $10 \mathrm{mM} \mathrm{NAC}+10 \mathrm{mM}$ NAM, suggesting a synergy effect.

Synergy parameter(s) were calculated using the relation:

$$
s=\frac{1-E_{1+2}}{1-E_{1+2}^{\prime}}
$$


Table 2. Synergistic factor, inhibition efficiencies and electrochemical parameters deduced for copper polarization curves in $1 \mathrm{M} \mathrm{HNO}_{3}$ in the absence and presence of inhibitors at $298 \mathrm{~K}$.

\begin{tabular}{ccccc}
\hline Concentration & $\mathrm{E}_{\text {corr }}(\mathrm{mV} / \mathrm{SCE})$ & $\mathrm{j}_{\text {corr }}\left(\mu \mathrm{A} \cdot \mathrm{cm}^{-2}\right)$ & $\eta(\%)$ & $s$ \\
\hline 0 & -38.90 & 80 & - & \\
10 mM NAC & -86.80 & 20.8 & 74 & - \\
10 mM NAM & -66.70 & 29.2 & 63.5 & - \\
Mixture & -90.40 & 11.00 & 86 & 0.70 \\
\hline
\end{tabular}

where $E_{1+2}$ and $E_{1+2}^{\prime}$ are the efficiencies of the mixture inhibitors calculated and measured, respectively.

$E_{1+2}$ can be expressed by:

$$
1-E_{1+2}=\left(1-E_{1}\right)\left(1-E_{2}\right)
$$

where $E_{1}=1-\frac{j_{\text {corr }}^{1}}{j_{\text {corr }}^{0}} ; \quad E_{2}=1-\frac{j_{\text {corr }}^{2}}{j_{\text {corr }}^{0}}$ and $E_{1+2}^{\prime}=1-\frac{j_{\text {corr }}^{0}-j_{\text {corr }}^{1+2}}{j_{\text {corr }}^{0}}$

$j_{\text {corr }}^{1}$ : corrosion current density in the presence of NAC, $j_{\text {corr }}^{2}$ : corrosion current density in the presence of NAM, $j_{\text {corr }}^{1+2}$ : corrosion current density in the presence of NAC and NAM (mixture), $j_{\text {corr }}^{0}$ : corrosion current density without inhibitor (blank).

$E_{1}$ and $E_{2}$, are the inhibitory efficiencies of each compound and the actual inhibitory efficiency of the mixture (NAC + NAM). The synergy parameter is the ratio of the calculated efficiency and the actual inhibition efficiency, the expression of (s) can be simplified by the following relation:

$$
s=\frac{j_{c o r r}^{1} \times j_{c o r r}^{2}}{j_{c o r r}^{0} \times j_{c o r r}^{1+2}}
$$

For the combination studied, the synergy parameter (s) calculated is 0.7 ( $\mathrm{s}<$ 1). So, the system is in the presence of a synergy that operates by a competitive adsorption [15].

\subsubsection{Electrochemical Impedance Spectroscopy (EIS)}

The synergistic effect of the two inhibitors has also been studied by electrochemical impedance spectroscopy (EIS) at the corrosion potential. Figure 3 presents the Nyquist impedance diagrams of copper after $1 \mathrm{~h}$ immersion in $1 \mathrm{M}$ $\mathrm{HNO}_{3}$ in the absence and in the presence of inhibitors $10 \mathrm{mM} \mathrm{NAC}, 10 \mathrm{mM}$ NAM and $10 \mathrm{mM} \mathrm{NAC}+10 \mathrm{mM}$ NAM.

The Nyquist diagrams (Figure 3) consist of two capacitive loops: one at high frequencies which is attributed to the resistance of the adsorbed species due to the adsorption of the inhibitory molecules on the surface of the copper and all other accumulated products, while that at lower frequency is generally attributed to the double layer capacitance and the charge transfer resistance. The diameter of the capacitive loop is greater in the case of the mixture than with the NAC and NAM alone indicating the synergistic effect of the combined inhibitors in the study medium) [16]. 


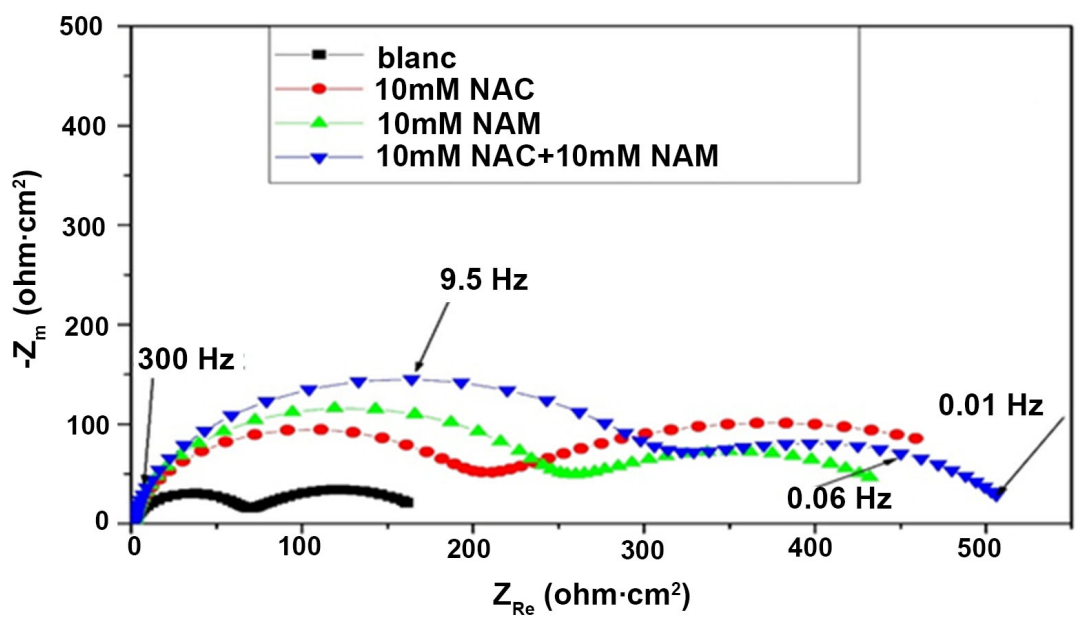

Figure 3. Nyquist diagrams of copper after 1 hour of immersion in $1 \mathrm{M} \mathrm{HNO}_{3}$ in the absence and presence of inhibitors.

In addition, Bode diagrams of copper after $1 \mathrm{~h}$ immersion in $1 \mathrm{M} \mathrm{HNO}_{3}$ in the absence and in the presence of different inhibitors alone and combined: (a) phase angles and (b) Bode modules are highlighted by Figure 4 .

Figure 4(a) confirms the existence of a second time constant in all three cases: this behavior reveals the presence of two different contributions. The first contribution located at high frequencies, can be associated with the film and the second with the charge transfer at the interface. It can also be noted that the greatest value of the phase angle is observed for the mixture. Bode's absolute impedance diagram (Figure 4(b)) shows that the impedance value increases considerably over the entire frequency range for inhibitors alone and combined with the greatest value for the combination. A larger value $|\mathrm{Z}|$ represents a better protection performance).To further analyze the impedance spectra, an equivalent electrical circuit with two constant time elements [17] was used to adjust the impedance data. This circuit is shown in Figure 5, where Rs is the resistance of the solution between the working electrode and the reference electrode, $\mathrm{Rf}$ is the resistance of the adsorbed layer formed on the copper surface, and Rct represents the charge transfer resistance related to the copper dissolution. The constant phase element CPE1 is composed of the capacitance Cf and the gap parameter $n_{1}$. The capacity $\mathrm{Cf}$ is mainly due to the dielectric nature of the surface film (corrosion products and/or an adsorbed inhibitor film). The CPE2 is composed of the double layer capacity $\mathrm{Cdl}$ and the $n_{2}$ gap parameter.

The impedance of the CPE is described as follows:

$$
Z_{C P E}=\left[Q(j w)^{n}\right]^{-1}
$$

where $Q$ is the magnitude of the $C P E, \mathrm{j}$ is the imaginary root, $w$ is the angular frequency, $n$ is the deviation parameter with respect to the phase shift.

The double layer capacity $(C)$ obtained from the CPE parameters was calculated from the following Brugg equation [18]: 


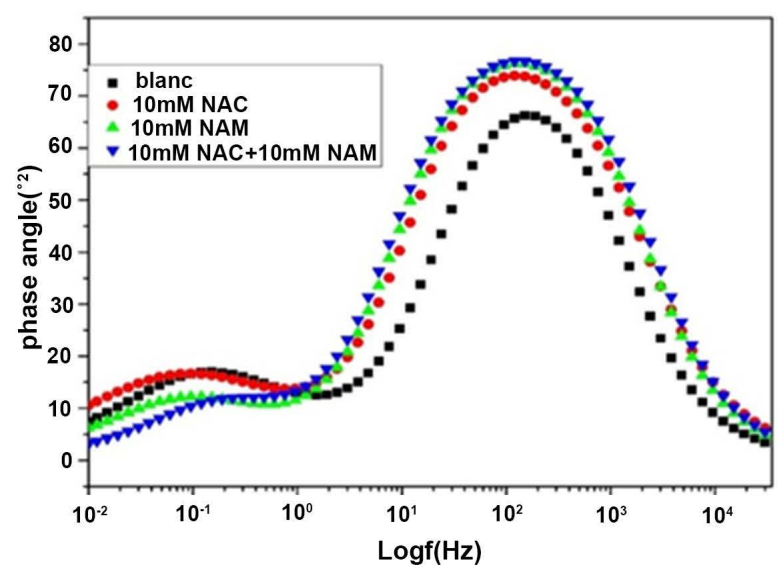

(a)

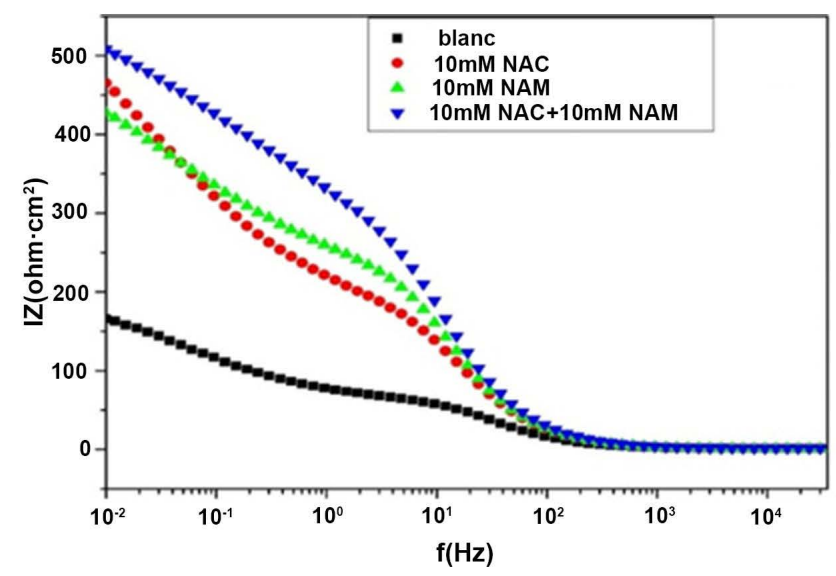

(b)

Figure 4. Bode diagrams of copper after $1 \mathrm{~h}$ immersion in $1 \mathrm{M} \mathrm{HNO}_{3}$ in the absence and presence of inhibitors: (a) phase angles and (b) Bode modules.

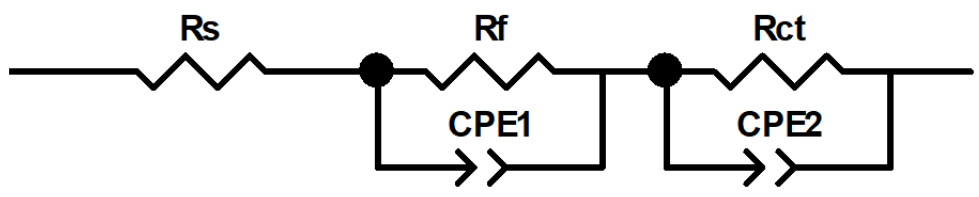

Figure 5. The equivalent electrical circuit used to fit the impedance spectra.

$$
C_{C P E}=\left[Q\left(R_{s}^{-1}+R_{c t}^{-1}\right)^{(n-1)}\right]^{\frac{1}{n}}
$$

The inhibition efficiency is calculated from the values of the polarization resistance $\mathrm{R}_{\mathrm{P}}\left(R_{p}=R_{f}+R_{c t}\right)$ using the following relationship:

$$
\eta=\frac{R_{p}^{i n h}-R_{p}}{R_{p}^{i n h}} \times 100
$$

The values of the electrochemical parameters and the inhibition efficiency $\eta(\%)$ for the single and combined inhibitors by electrochemical impedance spectroscopy are shown in Table 3.

Table 3 shows that the value of the polarization resistance $\left(R_{p}=R_{f}+R_{c t}\right)$ is higher in the presence of the mixture. It should also be noted that the double-layer capacity in the presence of inhibitors alone and combined is lower than that of the solution without inhibitor but lower in the case of the mixture. The increase of the polarization resistance $\left(R_{p}\right)$ results from an increase in the coverage of the metal surface by the inhibitor. The decrease in $C_{d l}$ is due to the adsorption of the inhibitory molecules replacing the water molecules at the met$\mathrm{al} /$ solution interface which causes a decrease in the local dielectric constant and/or an increase in the thickness of the electrical double layer) [19].

\section{Conclusion}

The mixture (10 mM NAC + 10 mM NAM) effectively inhibits the corrosion of 
Table 3. Electrochemical parameters and inhibition efficiency for copper corrosion in $1 \mathrm{M}$ $\mathrm{HNO}_{3}$ in the absence and presence of inhibitors.

\begin{tabular}{ccccccccc}
\hline Concentration & $\begin{array}{c}\mathrm{R}_{\mathrm{s}} \\
\left(\Omega \cdot \mathrm{cm}^{2}\right)\end{array}$ & $\begin{array}{c}\mathrm{R}_{\mathrm{f}} \\
\left(\Omega \cdot \mathrm{cm}^{2}\right)\end{array}$ & $\begin{array}{c}\mathrm{CPE}_{\mathrm{f}} \\
\left(\Omega \cdot \mathrm{S}^{\mathrm{n}} \mathrm{cm}^{-2}\right) 10^{-6}\end{array}$ & $\mathrm{n}_{1}$ & $\begin{array}{c}\mathrm{R}_{\mathrm{ct}} \\
\left(\Omega \cdot \mathrm{cm}^{2}\right)\end{array}$ & $\begin{array}{c}\mathrm{C}_{\mathrm{dl}} \\
\left(\mu \mathrm{F} \cdot \mathrm{cm}^{2}\right)\end{array}$ & $\mathbf{n}_{2}$ & $\begin{array}{c}\eta \\
(\%)\end{array}$ \\
\hline Blank & 1.515 & 61.97 & 160 & 0.93 & 122.3 & 2070 & 0,65 & - \\
$10 \mathrm{mM}$ NAC & 1.495 & 194.3 & 103 & 0.94 & 315.2 & 1129 & 0.71 & 63 \\
$10 \mathrm{mM}$ NAM & 1.462 & 241.7 & 90.47 & 0.94 & 205.9 & 1874 & 0.73 & 59 \\
Mixture & 1.471 & 296 & 81.14 & 0.95 & 225.4 & 994.6 & 0.74 & 65 \\
\hline
\end{tabular}

copper in both $3.5 \% \mathrm{NaCl}$ medium and $1 \mathrm{M} \mathrm{HNO}_{3}$ medium. In both cases, the combination behaves as a mixed type inhibitor with a great cathodic tendency. As far as the saline medium is concerned, we are witnessing an antagonistic effect of the NAM which can reduce the effectiveness of the NAC from $88 \%$ to $85 \%$. A synergistic effect by competitive adsorption $(\mathrm{s}<1)$ with an inhibition efficiency of $86 \%$ is observed in an acid medium. The impedance diagrams consist of two capacitive loops, one at low frequencies generally described as being representative of the charge transfer resistance at the metal/electrolyte interface and the other at high frequencies which may be associated with the film and other accumulated products. In the case of the mixture, the size of the capacitive loop is larger whereas the double layer capacity is smaller compared to the inhibitors alone. These observations confirm the synergistic effect of the two inhibitors in $1 \mathrm{M} \mathrm{HNO}_{3}$ medium.

\section{Acknowledgements}

The authors of the present paper are pleased to acknowledge Professor Juan CREUS for allowing the achievement of this work in his laboratory of La Rochelle University (France).

\section{Conflicts of Interest}

The authors declare no conflicts of interest regarding the publication of the present paper.

\section{References}

[1] Zhang, X., Zheng, Y., Wang, X., Yan, Y. and Wu, W. (2014) Corrosion Inhibition of N 80 Steel Using Novel Diquaternary Ammonium Salts in 15\% Hydrochloric Acid. Industrial and Engineering Chemistry Research, 53, 14199-14207. https://doi.org/10.1021/ie502405a

[2] Zhang, X., He, W., Wallinger, I.O., Pan, J. and Leygraf, C. (2002) Determination of Instantaneous Corrosion Rates and Runoff Rates of Copper from Naturally Patinated Copper during Continuous Rain Events. Corrosion Science, 44, 2131-2151. https://doi.org/10.1016/S0010-938X(02)00015-X

[3] Szöcs, E., Vestag, G., Shaban, A., Kouczos, G. and Kalman, E. (1999) Investigation of Copper Corrosion Inhibition by STM and EQCM Techniques. Journal of Applied 
Electrochemistry, 29, 1339-1345. https://doi.org/10.1023/A:1003869715760

[4] Kuznetsov, Y.I., Agafonkina, M.O., Shikhaliev, H.S. andeeva, N.P. and Potapov, A.Y. (2014) Adsorption and Passivation of Copper by Triazoles in Neutral Aqueous Solution. International Journal of Corrosion and Scale Inhibition, 3, 137-148. https://doi.org/10.17675/2305-6894-2014-3-2-137-148

[5] Wang, H., Wu, Q., Li, C.M. and Gu, N. (2013) Copper Corrosion Inhibition by Polyaspartic Acid and Imidazole. Materials and Corrosion, 64, 347-352. https://doi.org/10.1002/maco.201106261

[6] Ouedraogo, A., Diki, N.Y.S., Bohoussou, K.V., Soro, D. and Trokourey, A. (2018) Copper Corrosion Inhibition by Cefuroxime Drug in 1M Nitric Acid. Chemical Science Review and Letters, 7, 427-437.

[7] Zhang, D., Gao, L. and Zhou, G. (2004) Inhibition of Copper Corrosion in Aerated Hydrochloric Acid Solution by Heterocyclic Compounds Containing a Mercapto Group. Corrosion Science, 46, 3031-3040. https://doi.org/10.1016/j.corsci.2004.04.012

[8] Cohen, S.L., Brusic, V.A., Kaufman, F.B., Frankel, G.S., Motakef, S. and Rush, B. (1990) X-Ray Photoelectron Spectroscopy and Ellipsometry Studies of the Electrochemically Controlled Adsorption of Benzotriazole on Copper Surfaces. Journal of Vacuum Science and Technology A, 8, 2417-2424. https://doi.org/10.1116/1.576708

[9] Diki, N.Y.S., Gbassi, G.K., Ouedraogo, A., Berte, M. and Trokourey, A. (2018) Aluminum Corrosion Inhibition by Cefixime Drug: Experimental and DFT Studies. Journal of Electrochemical Science and Engineering, 8, 303-320.

https://doi.org/10.5599/jese.585

[10] Coulibaly, N.H., Brou, Y.S., Diomandé, G.D., Creus, J. and Trokourey, A. (2018) Nicotinic Acid as Green Inhibitor for Copper Corrosion in 3.5 wt \% NaCl Solution: Experimental and Quantum Chemical Calculations. International Journal of Biological and Chemical Sciences, 12, 1008-1027. https://doi.org/10.4314/ijbcs.v12i2.30

[11] Coulibaly, N.H., Brou, Y.S., Creus, J. and Trokourey, A. (2018) Nicotinamide Inhibition Properties for Copper Corrosion in 3.5\% NaCl Solution: Experimental and Theorical Investigations. Journal of Materials Science and Chemical Engineering, 6, 100-121. https://doi.org/10.4236/msce.2018.63008

[12] Tao, Z., He, W., Wang, S. and Zhou, G. (2013) Electrochemical Study of Cyproconazole as a Novel Corrosion Inhibitor for Copper in Acidic Solution. Industrial and Engineering Chemistry Research, 52, 17891-17899.

https://doi.org/10.1021/ie402693d

[13] Hosseini, M., Mertens, S.F.L. and Arshadi, M.R. (2003) Synergism and Antagonism in Mild Steel Corrosion Inhibition by Sodium Dodecylbenzenesulphonate and Hexamethylenetetramine. Corrosion Science, 45, 1473-1489.

[14] Barouni, K., Kassale, A., Albourine, A., Jbara, O., Hammouti, B. and Bazzi, L. (2014) Amino Acids as Corrosion Inhibitors for Copper in Nitric Acid Medium: Experimental and Theoretical Study. Journal of Materials Environmental Sciences, 5, 456-463.

[15] Rochdi, A., Kassou, O., Dkhireche, N., Touir, R., Bakri, M.E., Touhami, M.E., et al. (2014) Inhibitive Properties of 2,5-bis(n-methylphenyl)-1,3,4-oxadiazole and Biocide on Corrosion, Biocorrosion and Scaling Controls of Brass in Simulated Cooling Water. Corrosion Science, 80, 442-452. https://doi.org/10.1016/j.corsci.2013.11.067

[16] Zarrouk, A., Hammouti, B., Dafali, A. and Bentiss, F. (2013) Inhibitive Properties and Adsorption of Purpald as a Corrosion Inhibitor for Copper in Nitric Acid Medium. Industrial and Engineering Chemistry Research, 52, 2560-2568. 
https://doi.org/10.1021/ie301465k

[17] Gerengi, H., Ugras, H.I., Solomon, M.M., Umoren, S.A., Kurtay, M. and Atar, N. (2016) Synergistic Corrosion Inhibition Effect of 1-ethyl-1-methylpyrrolidinium Tetrafluoroborate and Iodide Ions for Low Carbon Steel in $\mathrm{HCl}$ Solution. Journal Adhesion Science and Technology, 30, 2383-2403. https://doi.org/10.1080/01694243.2016.1183407

[18] Córdoba-Torres, P., Mesquita, T., Devos, O., Tribollet, B., Roche, V. and Nogueira, R. (2012) On the Intrinsic Coupling between Constant-Phase Element Parameters $\alpha$ and $\mathrm{Q}$ in Electrochemical Impedance Spectroscopy. Electrochimica Acta, 72, 172-178. https://doi.org/10.1016/j.electacta.2012.04.020

[19] Behpour, M., Ghoreishi, S., Gandomi-Niasar, A., Soltani, N. and Salavati-Niasari, M. (2009) The Inhibition of Mild Steel Corrosion in Hydrochloric Acid Media by Two Schiff Base Compounds. Journal of Materials Science, 44, 2444-2453.

https://doi.org/10.1007/s10853-009-3309-y 